\title{
Parâmetros de potabilidade da água para o consumo humano: uma revisão
}

\section{integrativa}

\author{
Water potability parameters for human consumption: an integrative review \\ Parámetros de potabilidad del agua para el consumo humano: una revisión integradora
}

Recebido: 23/12/2021 | Revisado: 31/12/2021 | Aceito: 07/01/2022 | Publicado: 10/01/2022

\author{
Manoel das Virgens Souza Xavier \\ ORCID: https://orcid.org/0000-0003-0677-3576 \\ Faculdade de Tecnologia de Valença, Brasil \\ E-mail: juniormanuells.x@gmail.com \\ Helenita Costa Quadros \\ ORCID: https://orcid.org/0000-0002-7191-4809 \\ Fundação Oswaldo Cruz, Brasil \\ E-mail: helenita_quadros@hotmail.com \\ Monique Santos Sarly da Silva \\ ORCID: https://orcid.org/0000-0003-2756-7237 \\ Universidade Federal da Bahia, Brasil \\ E-mail: monique.sarly@ufba.br
}

\begin{abstract}
Resumo
Os recursos hídricos desempenham um papel importante na manutenção da vida humana, e, portanto, a relação entre a saúde humana e a qualidade da água distribuida para a sociedade têm sido cada vez mais discutida. Para ser considerada adequada para saúde da população humana, a água deve se encontrar em conformidade com parâmetros microbiológicos e físico-químicos indicados pelo Ministério da Saúde. Frente a isso, este trabalho teve como objetivo realizar uma revisão integrativa destacando os parâmetros de potabilidade da água para consumo humano, indicando suas fundamentações e importância. As pesquisas foram realizadas nas bases de dados do Google Scholar e Scientific Electronic Library Online (SciELO). Após avaliação criteriosa dos artigos, o total de 28 foram selecionados para o desenvolvimento deste trabalho. Os resultados indicaram que os parâmetros mais utilizados para avaliar a potabilidade da água foram os físicos, seguidos dos químicos e microbiológicos, e que estes implicaram diretamente no diagnóstico da qualidade da água. Deste modo, através deste estudo pode-se concluir que é imprescindível que haja parâmetros de pureza da água, assim como a realização de análises físicas, químicas e microbiológicas para avaliar e garantir a qualidade da água, além de impedir que doenças sejam transmitidas por veiculação hídrica.
\end{abstract}

Palavras-chave: Contaminação da água; Doenças de veiculação hídrica; Parâmetros de potabilidade e seus valores permissíveis na água.

\begin{abstract}
Water resources play an important role in the maintenance of human life, and, therefore, the relationship between human health and the quality of water distributed to society has been increasingly discussed. To be considered adequate for the health of the human population, water must comply with microbiological and physical-chemical parameters indicated by the Ministry of Health for human consumption, indicating its reasons and importance. Literature reviews were performed in Google Scholar and Scientific Electronic Library Online (SciELO) databases. After careful evaluation of the articles, a total of 28 were selected for the development of this work. The results indicated that the most used parameters to assess the potability of water were physical, followed by chemical and microbiological, and that these directly implied in the diagnosis of water quality. Thus, through this study, it can be concluded that it is essential to have water purity parameters, as well as physical, chemical, and microbiological analyzes to assess and guarantee the quality of water, in addition to preventing diseases from being transmitted by transmission water.
\end{abstract}

Keywords: Water contamination; Waterborne diseases; Potability parameters and their permissible values in water.

\section{Resumen}

Los recursos hídricos tienen un papel importante en el mantenimiento de la vida humana y, por lo tanto, la relación entre la salud humana y la calidad del agua distribuida a la sociedad se ha discutido cada vez más. Para ser considerada adecuada para la salud de la población humana, el agua debe cumplir con los parámetros microbiológicos y físico-químicos indicados por el Ministerio de Salud para el consumo humano, indicando sus razones e importancia. Las búsquedas se realizaron en las bases de datos de Google Scholar y Scientific Electronic Library Online (SciELO). Luego de una cuidadosa evaluación de los artículos, se seleccionaron un total de 28 para el desarrollo de este trabajo. Los resultados indicaron que los parámetros más utilizados para evaluar la potabilidad del agua fueron los físicos, 
seguidos de los químicos y microbiológicos, y que estos se implicaron directamente en el diagnóstico de la calidad del agua. Así, a través de este estudio se puede concluir que es fundamental contar con parámetros de pureza del agua, así como análisis físicos, químicos y microbiológicos para evaluar y garantizar la calidad del agua, además de prevenir la transmisión de enfermedades por transmisión hídrica.

Palabras clave: Contaminación del agua; Enfermedades de transmisión por agua; Parámetros de potabilidad y sus valores admisibles en agua.

\section{Introdução}

Os recursos hídricos desempenham um papel importante na manutenção da vida humana, dos ecossistemas e no desenvolvimento das populações (Oliveira, 2017). Isso se justifica no fato de serem amplamente utilizados para consumo da população, produção de alimentos, geração de energia, dentre tantas utilidades, possuindo, portanto, relevância na saúde, na qualidade de vida e no desenvolvimento das nações (De Assis, 2017).

Desde as civilizações antigas há uma preocupação em distribuir a água de maneira eficiente e segura para evitar a propagação de doenças associadas à via hídrica (Machado et al., 2021). Apesar disso, apenas a partir de 1980, começou-se a perceber e discutir a relação entre os malefícios à saúde humana e o sistema de abastecimento de água (Castro et al., 2020). Partindo desta premissa, a ideia da criação de regulamentos surgiu para assegurar que todos os meios de abastecimento de água fossem executados com êxito, garantindo a segurança sanitária e, portanto, evitando a proliferação das doenças de veiculação hídrica (Castro et al., 2020).

As doenças de veiculação hídrica podem ser classificadas como doenças de origem hídrica ou doenças de transmissão hídrica (Bezerra et al., 2017). As primeiras são geradas por substâncias orgânicas ou inorgânicas presentes na água em concentrações superiores aos padrões para consumo humano. Já a segunda, as doenças de transmissão hídrica, a água atua como condutor do agente infeccioso como, por exemplo, microrganismos patogênicos (Bezerra et al., 2017).

Doenças de transmissão hídrica são desencadeadas por patógenos que se desenvolvem e são transmitidos através da água contaminada, seja através da ingestão ou quando em contato com a pele e mucosas do corpo humano (Copasa, 2020). Com elas, podem surgir diferentes tipos de sintomas característicos, estando entre os mais comuns a diarréia, dor de barriga, perda de apetite, fraqueza e febre (Lopes, 2020). As principais doenças de veiculação hídrica correspondem à amebíase, giardíase, gastroenterite, febres tifoide e paratifoide, hepatite infecciosa e cólera (Souza, 2019). Além disso, indiretamente, a água também está ligada à transmissão de verminoses, como esquistossomose, ascaridíase, teníase, oxiuríase e ancilostomíase (Silva, 2018). Vetores, como o mosquito Aedes aegypti, que se relacionam com a água, podem ocasionar doenças como a dengue e a febre amarela (Copasa, 2020).

Por se tratar de um recurso de fundamental importância à vida, torna-se indispensável controlar e exigir a qualidade da água, por meio de regulamentos técnicos específicos e legislações que garantam saúde e bem-estar à população humana e animal (Birkheuer et al., 2017). A Portaria de Consolidação ${ }^{\circ}$ 5, de 28 de setembro de 2017, determina que deve-se realizar o controle e a vigilância da qualidade d água destinada ao consumo humano. Ainda de acordo com essa Portaria, para a garantia da potabilidade, a água deve estar em conformidade com o padrão microbiológico e de substâncias químicas que representam riscos à saúde (Brasil, 2017).

A potabilidade da água é avaliada por intermédio de análises laboratoriais. Tais análises correspondem a ensaios físico-químicos (cor, turbidez, condutividade elétrica, temperatura, pH, alcalinidade, dureza total, etc.) e métodos microbiológicos (coliformes totais e termotolerantes, e bactérias mesófilas aeróbias) conforme às Resoluções do Conselho Nacional do Meio Ambiente (CONAMA) 430/2011 (Brasil, 2011) 396/2008 (Brasil, 2008) e a 357/2005 (Brasil, 2005), e também conforme a Portaria GM/MS no 888, de 4 de maio de 2021, do Ministério da Saúde (MS) (Brasil, 2021). Em vista do que fora apresentado acima, o objetivo desse trabalho foi realizar uma revisão integrativa a respeito dos parâmetros de potabilidade da água para consumo humano. 


\section{Metodologia}

Este trabalho consiste em uma revisão integrativa de artigos científicos referentes aos parâmetros de potabilidade da água para consumo humano. Para o desenvolvimento da pesquisa, seguiram-se as seguintes etapas: definição do problema de pesquisa, busca nas bases e bancos de dados científicos, avaliação crítica das evidências encontradas e discussão dos trabalhos obtidos (Figura 1).

Figura 1. As etapas para elaboração da pesquisa científica.

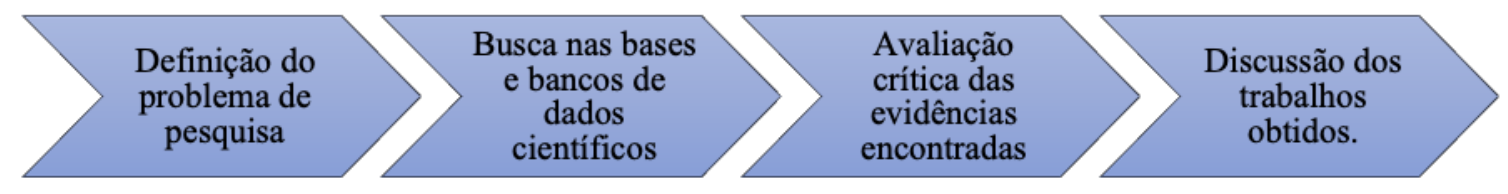

Fonte: Autores.

Com base no delineamento de elaboração da pesquisa previamente apresentado, desenvolveu-se as seguintes questões norteadoras: Quais são os indicadores que determinam a potabilidade da água? Quais são os critérios de potabilidade da água mais seguros para o consumo humano? Os parâmetros atuais são suficientes? Uma vez estabelecidas estas questões, o levantamento de dados para essa pesquisa ocorreu entre os meses de abril e maio de 2021 utilizando as seguintes bases de dados: Google Scholar e Scientific Electronic Library Online (SciELO).

Para a seleção dos artigos, utilizou-se como critérios de inclusão: artigos originais publicados em português, disponíveis na íntegra e com recorte temporal de publicação dos últimos cinco anos (2017 - 2021), e que tenham abordado temas relacionados aos parâmetros de potabilidade da água para consumo humano. Como critérios de exclusão, destacaram-se: teses, dissertações, monografias, editoriais e estudos de caso, além das repetições de publicação de estudos em mais de uma base de dados; também, os artigos que possuíam análises e metodologias que não se encaixassem com a proposta da pesquisa, bem como que não estivessem escritos na língua portuguesa. As palavras-chaves utilizadas na pesquisa foram: "Contaminação da água", "Doenças de veiculação hídrica" e "Parâmetros de potabilidade e seus valores permissíveis na água".

Uma vez aplicados os critérios de inclusão e exclusão, os artigos foram selecionados da seguinte maneira: 1) leitura dos títulos, 2) leitura dos resumos e 3) leitura de todos os artigos na íntegra; a partir disto, os artigos selecionados foram analisados criteriosamente. Feito isto, foi realizada uma categorização em recortes temáticos, com o intuito de descrever e classificar os resultados, a fim de evidenciar os achados mais atuais acerca da potabilidade da água para consumo humano.

\section{Resultados}

A respectiva revisão integrativa iniciou-se com a leitura dos títulos dos artigos, acarretando em um cumulativo de 6.231 artigos completos publicados e disponíveis nas bases de dados (SciELO e Google Scholar). Em seguida, após a leitura dos títulos, apenas 84 estudos foram mantidos, os quais, os seus resumos também foram criteriosamente avaliados. Assim, dos 84 estudos, restaram 40, que, por conseguinte, foram lidos na íntegra. Por último, selecionou-se 28 estudos de maior interesse que contribuíam para a temática estudada (Figura 2). 
Figura 2. Fluxograma das etapas da seleção dos artigos de interesse.

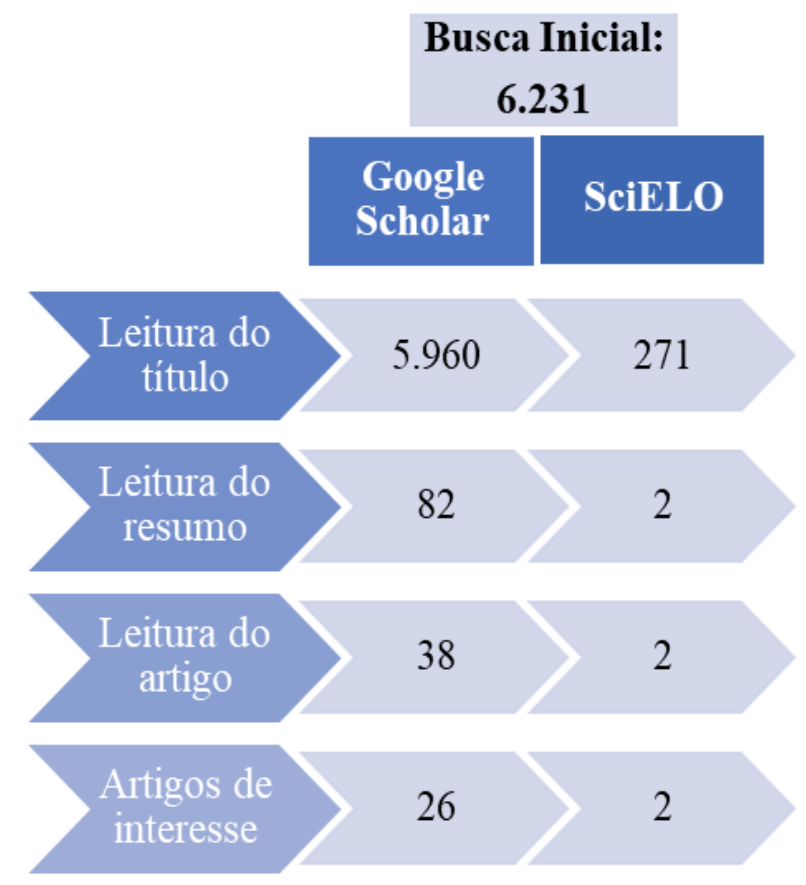

Fonte: Autores.

Os resultados desse estudo indicaram que os parâmetros e indicadores mais descritos na literatura para verificar a potabilidade da água incluem, principalmente, os físicos, tais como: cor, turbidez, temperatura, sabor e odor. Além dos parâmetros físicos, percebe-se também uma frequência na utilização de parâmetros químicos, entre os quais destacam-se o pH, alcalinidade, acidez e dureza (Silva et al. 2017; Filho, 2019; Lima et al. 2019; Nolasco et al. 2020; Silva et al. 2020). Por último, análises microbiológicas utilizando organismos indicadores, algas e bactérias, também se mostraram extremamente relevantes.

No geral, foram encontrados 28 (vinte e oito) estudos que apresentavam resultados e valores que atendiam os padrões de potabilidade para consumo humano determinados pelo MS, assim como estudos que não estavam em conformidade com os padrões determinados pelo MS. A maioria dos artigos, entretanto, indicou contaminação da água através de parâmetros microbiológicos $(n=12)$ e físico-químicos $(n=09)$, conforme observado por ordem cronológica e, em seguida, ordem alfabética no Quadro 1. 
Quadro 1. Síntese dos estudos selecionados para a pesquisa.

\begin{tabular}{ccc}
\hline Autor (es) & Ano & Título \\
& & \\
Ferreira et al. & 2021 & $\begin{array}{c}\text { Avaliação da qualidade de } \\
\text { potabilidade da água subterrânea } \\
\text { em áreas rurais no município de } \\
\text { Humaitá no Amazonas (AM). }\end{array}$
\end{tabular}

Molluce 2021

Silva et al. $2021 \mathrm{a}$

Silva, et al.

Avaliação de risco relativo de doenças de veiculação hídrica provenientes de fontes de abastecimento individual de água subterrânea localizadas no bairro Guriri, São Mateus, Espírito Santo (ES). microbiológica e físico-química da água de um trecho do Rio Capibaribe, no município de São Lourenço da Mata, Pernambuco (PE).

Qualidade físico-química e bebedouros de instituições de ensino no Brasil: revisão sistemática da literatura

Monitoramento de variáveis ambientais e avaliação do índice de qualidade da água em viveiro de
Estudo da potabilidade da água e a importância de seu controle de qualidade no fluxo de produção das indústrias farmacêuticas.
Avaliar a potabilidade da água e a importância do seu controle de qualidade no fluxo de produção das indústrias farmacêuticas.

Avaliar as características físicas, químicas e microbiológicas da água subterrânea dos poços de abastecimento das comunidades rurais do município de Humaitá, no AM, visando fornecer dados como subsídio para segurança hídrica e comparar com os padrões de potabilidade.

Avaliar a potabilidade e os níveis de microbiológica da água utilizada em piscicultura.
Avaliar a qualidade físico-química e microbiológica da água utilizada em bebedouros de instituições de ensino no Brasil.
Monitorar a qualidade da água de um viveiro de piscicultura com policultivo de espécies de peixes, através da avaliação de variáveis ambientais.
Avaliação da qualidade

Verificou-se que os tipos de águas utilizadas nos processos das indústrias farmacêuticas encontram-se em conformidade com os parâmetros nas

farmacopeias e nas portarias da Agência Nacional de Vigilância Sanitária.

Os resultados apontaram altos níveis de contaminação bacteriana, uma vez que $90,47 \%$ das amostras de água subterrânea atestaram presença de coliformes totais e $28,57 \%$ apresentaram valores positivos para E. coli.

Os parâmetros $\mathrm{pH}$, turbidez, sulfato, dureza total das análises estão de acordo com a Resolução 357/05 do CONAMA. Porém, apresentou baixos níveis de oxigênio dissolvido, condutividade elétrica, cloretos e a cor.

Foi observada a presença de coliformes totais e termotolerantes. Além disso, os valores de cloretos, $\mathrm{pH}$, cloro residual livre, cor, alumínio, turbidez, fluoretos, não estavam em conformidade com a legislação vigente.

Análise da qualidade da água de uma nascente localizada no bairro do Registro, Taubaté, SP - Brasil.
Realizar análises de potabilidade da água de uma nascente utilizada para consumo de moradores de um bairro rural da cidade de Taubaté.
Contaminação microbiológica por coliformes totais e E. coli em todas as amostras coletadas.

Foram detectadas altas concentrações de ferro e a presença de coliformes termotolerantes (E. coli, bactérias heterotróficas e coliformes totais). Valores apresentados estavam fora dos limites exigidos pelas normas para o padrão de potabilidade. 


Avaliação da qualidade da água em
bebedouros de escolas de Ensino
Fundamental I da cidade do Sertão
do Pajeú, PE.

Nolasco et al.

Silva et al. $2020 \mathrm{a}$

Silva et al. $2020 b$
Análise da alcalinidade, cloretos, dureza, temperatura e condutividade em amostras de água do município de Almenara, em Minas Gerais (MG). por bebedouros destinados ao consumo humano e sua relação com a saúde.

Qualidade da água designada ao abastecimento público de rio Branco, no Acre.

Potabilidade da água de cacimbas: estudo de caso em um distrito da cidade de Barro, Ceará.

Avaliação dos parâmetros físicoquímicos e microbiológicos de água potável de hospitais das cidades de Crato e Juazeiro do Norte, no CE.

Caracterização da qualidade da água de Pau dos Ferros quanto a parâmetros físico-químicos.
Qualidades das águas fornecidas
Determinar a qualidade da água, verificando a possível presença de coliformes totais e fecais, bem como mensurar os valores de $\mathrm{pH}$ e de cloretos.

Realizar análises de alcalinidade, cloretos, dureza, temperatura e condutividade em amostras de água do município de Almenara, (MG).

Avaliar a estrutura física dos bebedouros e a qualidade da água para consumo humano fornecida no Campus Universitário Paulo VI da Universidade Estadual do Maranhão.

Analisar os parâmetros de qualidade da água tratada em uma estação de tratamento localizada na cidade de Rio Branco, Acre, e verificar sua aplicabilidade ante as legislações vigentes.

Verificar a qualidade físico-química e microbiológica da água de cacimbas que são utilizadas para diversos fins em um distrito da cidade de Barro, Ceará

Analisar as características físicoquímicas e microbiológicas de água potável de dois hospitais da cidade de

Crato e um hospital de Juazeiro do

Norte, CE, e compará-los com os padrões de potabilidade.

Caracterizar, quanto a aspectos físicoquímicos, a qualidade da água abastecida em residências do município de Pau dos Ferros, no Rio Grande do Norte (RN).
Em nenhuma das escolas analisadas foi registrada a presença de E. coli, porém 4 amostras apresentaram coliformes totais. Os teores de cloretos estavam em conformidade com a legislação.

As amostras apresentaram seus parâmetros de acordo com os determinados pela legislação.

Cerca de $5 \%$ dos bebedouros estavam em estado duvidoso, por causa de avarias na sua estrutura física. As análises físico-químicas revelaram que a água dos bebedouros estava dentro dos padrões estabelecidos, exceto a acidez. $100 \%$ das amostras continham bactérias heterotróficas, $75 \%$ coliformes totais e $25 \%$ Pseudomonas.

As análises de $\mathrm{pH}$ variaram de 5,1 a 6,9 , com uma média de 6,4 na água tratada; a turbidez apresentou uma média de 1,5 uT; a cor ficou em uma faixa de 0 a $1 \mathrm{Uh}$; e a concentração de cloro residual livre apresentou uma faixa 0,8 a 3,0 mg/L, estando acima do valor máximo permitido.

As amostras de água apresentaram um padrão de qualidade

estabelecido dentro dos parâmetros físico-químicos, entretanto, alterações em dureza, e aos teores de nitrato e ferro foram observadas. Todas apresentaram contaminação microbiológica por coliformes totais.

Ausência de coliformes em 100 $\mathrm{mL}$ de amostra. Os resultados para $\mathrm{pH}$ e cloro residual nos hospitais A e $\mathrm{C}$ foram inferiores, sendo impróprias para consumo humano. Apenas o hospital B apresentou todos os parâmetros de acordo com o exigido pela Portaria.

Dos valores analisados, apenas turbidez e $\mathrm{pH}$ estavam em desconformidade com a norma. Condutividade foram em média $457,33 \mu \mathrm{s} / \mathrm{cm}$ e oxigênio dissolvidos apresentaram os teores de oxigênio muito superiores ao indicado. 
Landa et al. 2019 como método de preservação de nascentes e da qualidade dos mananciais.

Lima et al.

Avaliação de parâmetros de potabilidade da água e de consumo do Instituto Federal Catarinense (IFC), no Campus Araquari.

\section{Oliveira \\ et al.}

Santos et al.

Sousa et al.

Assis

Cruz

Leite et al.

Rabelo et al.

Análise físico-química e microbiológica da água e bebedouros de escolas municipais na Cidade de Jardim, no Ceará.

Determinação de propriedades

físico-químicas de águas do Chafariz do município de Cuité, na Paraíba (PB).

Análise da qualidade da água de três propriedades rurais do município de Floriano- Piauí.

Potabilidade da água de abastecimento público de formiga, em MG.

Parâmetros físico-químicos e microbiológicos da água dos bebedouros de escolas públicas estaduais de tempo integral de Teresina, Piauí (PI).

Análise físico-química e microbiológica da água de bebedouros do Instituto Federal do Maranhão - Campus Codó.

Análise dos parâmetros físicoquímicos e microbiológicos da água do rio Paciência, São Luís, Maranhão (MA).
Comparar duas nascentes, quanto a sua conservação, analisando os parâmetros físico-químicos (oxigênio dissolvido, $\mathrm{pH}$, cor, turbidez) e microbiológicos (coliformes totais, fecais e salmonela) de qualidade da água.

Avaliar a qualidade da água de consumo do IFC, Campus Araquari

As quatro nascentes estudadas estavam de desacordo com a legislação vigente, sem condições de potabilidade, e apresentaram a capacidade de transmitir enfermidades de veiculação hídrica.

Foi constatada contaminação por coliformes termotolerantes nos três pontos de amostragem. $\mathrm{O}$ teor de nitrato e os valores de dureza estavam fora dos limites aceitáveis para consumo. Já o pH, o cloreto e os sólidos totais dissolvidos apresentaram resultados dentro dos limites aceitáveis.

Duas escolas apresentaram água potável, pura e de qualidade, porém uma das três escolas apresentou indícios de contaminação bacteriana por coliformes totais.

As amostras atendem aos padrões de potabilidade exigido pelo MS

Analisar a potabilidade da água de três comunidades rurais da cidade de Floriano-PI, por meio de parâmetros físico-químicos e microbiológicos.

Realizar um estudo temporal no município de Formiga, MG, para verificar a potabilidade da água utilizada para abastecer a população urbana.

Avaliar os parâmetros físico-químicos e microbiológicos das águas das escolas públicas de tempo integral da cidade de Teresina, no PI.

Analisar a qualidade físico-química e microbiológica da água dos bebedouros do Instituto Federal do Maranhão Campus Codó.

Identificar os parâmetros físicoquímicos e microbiológicos da água do Rio Paciência, São Luís, MA.
As amostras avaliadas indicaram a potabilidade da água, visto que as mesmas encontraram - se dentro dos valores máximos estabelecidos pela Portaria do MS

A água fornecida pelo sistema de abastecimento público de Formiga estava apta para o consumo humano.

Todas as amostras apresentaram-se satisfatórias para as análises microbiológicas e $85 \%$ para as análises físico-químicas

Os pontos avaliados se encontraram dentro da maioria dos parâmetros físico-químicos exigidos pela legislação e fora dos padrões microbiológicos, apresentando contaminação pelos grupos coliformes totais e fecais.

Dos parâmetros físico-químicos analisados, o pH, a salinidade e os sólidos totais dissolvidos estavam enquadrados na Resolução

CONAMA 357/05. As análises microbiológicas realizadas constataram a presença de coliformes totais e $E$. coli. 


Bezerra et al. $2017 \quad \begin{gathered}\text { Análise da potabilidade de água de } \\ \text { chafarizes de dois bairros do } \\ \text { município de Fortaleza, Ceará. }\end{gathered}$
município de Fortaleza, Ceará.

Qualidade físico-química e microbiológica da água de consumo

Birkheuer et al.

2017 humano e animal do Brasil: análise sistemática.

Silva

2017

Silva et al

2017

Parâmetros físico-químicos da água utilizada para consumo nas escolas municipais da zona urbana de Esperança, na PB.

Avaliação dos parâmetros da qualidade de água produzida na estação de tratamento de água oeste.

Avaliação da qualidade da água e a

Soares; Ferreira.

2017
Analisar a potabilidade da água de chafarizes dos bairros Lagoa Redonda e Curió do município de Fortaleza, CE.

Quantificar pesquisas bibliográficas referentes à qualidade físico-química e microbiológica da água destinada ao consumo humano e animal, a fim de analisar se estão dentro dos padrões exigidos pelas legislações vigentes.

Monitorar e avaliar os parâmetros de qualidade da água produzida no sistema operacional da ETA Oeste, através da realização de análises físico-químicas.

Verificar alguns parâmetros físicoquímicos da água que abastece as escolas municipais da zona urbana da cidade de Esperança, PB.

Discutir o monitoramento da qualidade da água no Brasil e no mundo, com a revisão dos parâmetros de avaliação da qualidade da água.
$37,5 \%$ das amostras estavam com o pH abaixo do recomendado, $25 \%$ estavam com teores de nitrato acima do permitido e $62,5 \%$ das amostras apresentaram-se positivas para contaminação bacteriológica.

Os achados concluíram que há poucas pesquisas em relação a qualidade físico-química e microbiológica das águas destinadas ao consumo humano e, principalmente, animal.

Evidenciou-se a conformidade do processo de tratamento de água na estação.

As amostras atenderam aos padrões com relação ao $\mathrm{pH}$ e ao teor de cloreto;As demais - a cor aparente e alcalinidade média apresentaram valores fora da faixa permitida.

As análises das características microbiológicas impulsionaram avanços às novas tecnologias.

Sugeriram também a inclusão da identificação de vírus, bactérias não coliformes e alguns protozoários.

Fonte: Autores.

\section{Discussão}

O padrão de potabilidade da água determinado no Brasil é composto pelos padrões organoléptico, microbiológico, de radioatividade e de substâncias químicas (inorgânicas, orgânicas, agrotóxicos, desinfetantes e produtos secundários da desinfecção) que representam risco à saúde humana (Ministério da Saúde, 2017). Assim, para entender os padrões de potabilidade, as análises dos parâmetros físico-químicos da água são realizadas com o propósito de obter informações a respeito da qualidade da água, e, também, de identificar e monitorar possíveis efeitos negativos da mesma para a saúde humana ou aos outros organismos que utilizam este recurso (Silva et al., 2017). Neste contexto, as características físicas da água estão associadas à ordem estética, obedecendo parâmetros estabelecidos, tais como cor, temperatura, sabor e, odor; contudo, ressaltase que preferência pela água de melhor aparência não garante qualidade adequada ao consumo, uma vez que substâncias dissolvidas que não alteram necessariamente a cor, podem estar alterando outros parâmetros da água, como a alcalinidade, o oxigênio dissolvido e o pH (Santos et al., 2019).

O parâmetro "cor da água" é derivado do reflexo da luz em partículas pequenas contidas nesse componente natural, e a intensidade deste reflexo é determinada utilizando cobalto-platina como referência, representado em unidades de cor uH (unidade Hazen) (Filho, 2019). O MS estabelece o valor de 15 uH como Valor Máximo Permitido (VPM) para os níveis de cor aparente na água tratada (Ministério da Saúde, 2017). De fato, a cor é resultante da presença de substâncias dissolvidas, e, enquanto pura e em grandes volumes, a água é azulada. Assim, partindo desse princípio, quando há elevadas concentrações de ferro e ácidos húmicos na água, a mesma apresenta-se avermelhada e amarelada, respectivamente (Silva et al., 2021).

Desta maneira, a cor da água pode ser classificada como cor verdadeira, na qual se refere à determinação de cor em amostras sem turbidez, portanto, é considerada como aquela que não sofre com a presença das partículas suspensas na água, ou 
seja, após a matéria ou partículas terem sido removidas por meio do processo de centrifugação ou filtração, desta forma é possível estabelecer a cor de maneira mais fidedigna. Por outro lado, existe a cor real ou aparente que é medida sem submeter a amostra a nenhuma remoção de partículas, no que diz respeito à determinação de cor em amostras com turbidez seja com material coloidal ou em suspensão (Filho, 2019).

A temperatura é considerada uma medida de intensidade de calor que influencia diretamente uma série de outros parâmetros físicos como a viscosidade, densidade, oxigênio dissolvido (OD) tensão superficial, compressibilidade, calor específico, constante de ionização, calor latente de vaporização, condutividade térmica e na pressão de vapor (Nolasco et al., 2020). Além disso, a temperatura pode variar em função de fontes naturais (energia solar) e fontes antropogênicas, despejos industriais e águas de resfriamento de máquinas (Soares, 2017). A Portaria do Ministério da Saúde MS nº 5/2017 não determina limites para temperatura, no entanto, o seu levantamento deve ser realizado, pois conforme mencionado anteriormente, este parâmetro influencia na quantidade de oxigênio dissolvido e também na troca de gases presentes no meio aquoso com a atmosfera, bem como na quantidade encontrada nas tubulações de abastecimento urbano que passam por exposição à radiação solar (Nolasco et al., 2020). Outrossim, segundo a Fundação Nacional da Saúde (FUNASA), a temperatura apresenta relevante influência na velocidade das reações químicas, nas atividades metabólicas dos organismos e, também, na solubilidade de substâncias (Bauchspiess, 2020).

Destacada como um relevante parâmetro físico-químico, a condutividade elétrica é conhecida como a capacidade da água natural de transmitir a corrente elétrica em função da presença de substâncias dissolvidas que se dissociam em ânions e cátions, e a unidade escolhida para sua representação é a de resistência ohm ou S (unidade de medida da resistência elétrica), por unidades de comprimento cm (centímetro) ou m (metro) (Filho, 2019). Diante disso, para determinar a condutividade elétrica, devem ser avaliados usualmente íons de ferro (Fe) e manganês (Mn), além de (potássio) K+, (cloro) Cl-, (sódio) Na+, (cálcio) $\mathrm{Ca}^{2}+$, (magnésio) $\mathrm{Mg}^{2}+$, os quais, por consequência, apresentam uma proporção direta à concentração iônica (Silva et al., 2017). Além da concentração iônica, a condutividade elétrica também depende da temperatura, a qual influi na quantidade de sais existentes na coluna d'água e, portanto, representa uma medida indireta da concentração de poluentes. Níveis superiores a $100 \mu \mathrm{S} / \mathrm{cm}$ sinalizam ambientes impactados (Cetesb, 2020).

Além dos parâmetros físico-químicos, existem os parâmetros organolépticos, como gosto e odor, os quais trata-se de características claramente perceptíveis da água. O gosto e o odor podem ser modificações durante a distribuição da água, devido ao contato direto com as tubulações que, ao longo dos anos, sofrem com o fenômeno da corrosão e podem ter se tornado propício ao crescimento de microrganismos. Diante disso, presume-se que gosto e odores incomuns são possíveis indicativos de água contaminada ou poluída (Filho, 2019). Nesse contexto, uma água sem odor geralmente é considerada isenta de contaminantes, no entanto, a presença de odor como o do sulfeto de hidrogênio indica a decomposição de substâncias orgânicas. Compostos orgânicos degradados pelas atividades dos microrganismos e algas são geralmente responsáveis pelo mau odor notado nas águas marinhas (Molluce, 2021).

A turbidez também é considerada uma propriedade importante dos fluidos e está associada à presença de partículas em suspensão (poluição, plânctons, argila, bactérias e areia) que impedem a passagem de luz na água (Birkheuer et al., 2017). A determinação da turbidez é realizada por meio do método nefelométrico. O princípio desse método se baseia na comparação da intensidade de luz espalhada pela amostra em condições definidas, em comparação com a intensidade de luz atravessada por uma suspensão que contém um padrão de referência, com os mesmos critérios e condições, somado a isso percebe-se que, quanto maior for a intensidade da luz espalhada maior será a turbidez da amostra (Silva, 2017). Altas taxas de turbidez na água indicam a presença de flocos pesados que decantam mais rapidamente quando comparados com as amostras que apresentam baixa turbidez (Araújo; Andrade, 2020). Conforme padrões estabelecidos, o valor máximo permitido do padrão de turbidez da água resultante de filtração rápida, do tratamento completo ou considerada também como filtração direta é cerca de 0,5 uT 
(unidade de turbidez); bem como o valor máximo permitido para água resultante de filtração lenta a turbidez é de 1,0 uT. Em vista disso, o valor limite máximo para qualquer amostra pontual deve ser de 5,0 uT para turbidez como padrão organoléptico de potabilidade (Araújo; Andrade, 2020).

Os sólidos totais dissolvidos nas águas representam toda a matéria que permanece como resíduo, após evaporação, secagem ou calcinação da amostra a uma temperatura pré-estabelecida durante um tempo fixo (Santos et al., 2019). Sólidos em suspensão podem ser caracterizados como partículas passíveis de retenção por processos de filtração (Bauchspiess, 2020). Já os sólidos dissolvidos são constituídos por partículas de diâmetro inferior a $10{ }^{3}$ ( $\mu \mathrm{m}$ ) (micrômetro) e que permanecem em solução mesmo após a filtração (Filho, 2019; Santos et al., 2019). A necessidade da análise de sólidos totais dissolvidos se deve ao fato de que em grande ou baixa quantidade, o consumo da água com esses níveis pode acarretar problemas e danos à saúde. Como por exemplo, o excesso de magnésio no corpo o qual pode provocar fraqueza muscular, pressão baixa, rubor na face, náuseas e insuficiência respiratória (Lima et al., 2019).

A alcalinidade da água é outro parâmetro importante a ser analisado e é medida por meio da quantificação de sais alcalinos, principalmente de sódio e cálcio. Este parâmetro mede a capacidade da água de neutralizar os ácidos resultante da presença de carbonatos, bicarbonatos e hidróxidos, isto é, a quantidade de substâncias que atuam como um tampão. Se estes estiverem em teores elevados, podem proporcionar sabor desagradável à água, dessa maneira, para o consumo humano o valor máximo permitido para alcalinidade inferior a $150 \mathrm{mg} . \mathrm{L}^{1}{ }^{1}$, entretanto, até $250 \mathrm{mg}$. L-1 $^{1}$ é atendível ( Bezerra et al., 2018).

O potencial hidrogeniônico $(\mathrm{pH})$ representa a intensidade das condições ácidas ou alcalinas do meio líquido por meio da medição da presença de íons Hidrogênio (Santos et al., 2019). Trata-se de um parâmetro importante para a avaliação da qualidade da água, pois a acidez aumentada pode causar problemas quanto a utilização das águas para fazer higienização (Araújo; Andrade, 2020). Esse parâmetro pode neutralizar os agentes desinfetantes como o hipoclorito de cálcio, o cloro e ácido peracético que são comumente utilizados para remoção dos microrganismos (Araújo; Andrade, 2020). O valor do pH não só influencia na dissipação das formas livres e ionizada de vários compostos químicos, como também contribui para um maior ou menor grau de grau de solubilidade das substâncias e de determinar o potencial de toxidade de diversos elementos (Cruz, 2018). Desta maneira, ressalta-se que a água com pH abaixo de 6,0 é classificada como ácida e corrosiva e acima de 9,5 como básica, contribuindo para precipitação de sais e incrustações dos mesmos, assim o pH é essencial para manter em boas condições as tubulações que conduzem a água as residências (Souza; Sousa, 2020). O valor do pH indicado para a proteção à vida se estabelece entre 6 e 9, reiterado pela Portaria de Consolidação do Ministério da Saúde, MS (2017) na qual recomendase que, no sistema de distribuição, o pH da água deva ser mantido na faixa de 6,0 a 9,5 (Cetesb, 2018). Quando o pH apresenta valores superior a 7,0 propiciam o aumento da alcalinidade, comprometendo a potabilidade e o consumo da água (Sousa et al., 2019).

Outro parâmetro importante e frequentemente utilizado para avaliação da qualidade e potabilidade da água é o OD. As variações quantitativas do OD estão intimamente relacionadas à processos físicos, químicos e biológicos que ocorrem nos corpos d'água. A solubilidade do oxigênio diminui à medida que a temperatura e a salinidade aumentam (Filho, 2019). A concentração de oxigênio influencia nos processos biológicos da água, de modo que índices que demonstram concentrações menores que $5 \mathrm{mgL}^{-1}$ podem modificar a sobrevivência das comunidades biológicas, e menor que $2 \mathrm{mgL}^{1}$ podem causar a morte dos seres aquáticos (Filho, 2019).

Além dos parâmetros químicos e físicos, há os parâmetros microbiológicos, os quais também são considerados na avaliação da potabilidade da água. De acordo com a Portaria de Consolidação $\mathrm{N}^{\circ}$ 5, de 28 de setembro de 2017 do Ministério da Saúde MS, a água adequada ao consumo humano deve estar livre de Escherichia coli e de bactérias do grupo dos coliformes totais em cada $100 \mathrm{~mL}$ de amostra testada (Tabela 1) (Brasil, 2017). A análise da contagem padrão de bactérias mesófilas aeróbias confirma a qualidade microbiológica das etapas do tratamento da água. Apesar da maioria das bactérias comuns 
presentes na água não serem patogênicas, isso indica risco à saúde, além de reduzir a qualidade da água e favorecendo odores e sabores desagradáveis, como por exemplo (Birkheuer et al., 2017).

Tabela 1. Padrões microbiológicos da água para consumo humano.

\begin{tabular}{cc}
\hline PARÂMETRO & ESPECIFICAÇÃO \\
\hline Coliformes Totais & Ausência em $100 \mathrm{~mL}$ \\
Coliformes Termotolerantes & Ausência em $100 \mathrm{~mL}$ \\
Escherichia coli & Ausência em $100 \mathrm{~mL}$ \\
\hline
\end{tabular}

Fonte: Adaptado da Portaria MS nº 5, de 28 de setembro de 2017.

Os grupos de bactérias Coliformes pertencem a família Enterobacteriaceae, constituindo-se de bactérias gramnegativas que não formam esporos, encontradas no trato intestinal dos animais de sangue quente (Landa et al., 2019). Essas bactérias podem ser anaeróbias ou aeróbias facultativos dispondo da capacidade de fermentação de lactose à $35^{\circ} \mathrm{C}$ entre 24 e 48 horas (Lima; Santos; Silva, 2020). Os coliformes podem ser classificados como coliformes totais e termotolerantes. Estruturado por um número de bactérias, o grupo coliforme é integrado pelos gêneros Klebsiella, Escherichia, Serratia, Erwenia e Enterobactéria. A presença de bactérias desse grupo na água é responsável por variadas doenças, sobretudo, as infecções intestinais (Landa et al., 2019). Essas bactérias são usadas em grande escala nas medições microbiológicas que avaliam a qualidade da água e de alimentos para que as pessoas consumam sem maiores riscos (Lima et al., 2019).

A E. coli é o principal representante das bactérias indicadoras de contaminação fecal, constituindo-se como um coliforme termotolerante, ou seja, possui capacidade de fermentar lactose a $44-45^{\circ} \mathrm{C}( \pm 0,2)$ em 24 - 48 horas. A ingestão deste microrganismo por meio de água contaminada e alimentos em situações higiênicas precárias pode ocasionar vômitos, febre, mal-estar, diarreia, calafrios, cólica e quadros graves de diarreia sanguinolenta (Cruz, 2018). A conformidade das amostras para os parâmetros microbiológicos é importante porque contribui para a manutenção da saúde humana (Araújo; Andrade, 2020). No entanto, diversos estudos constataram a presença tanto de coliformes totais, bem como os termotolerantes em amostras de água para o consumo humano, não sendo adequadas para o consumo humano e se encontram em desconformidade com o anexo XX da Portaria de Consolidação (PC) n ${ }^{\circ}$ 05/2017, recentemente substituída pela Portaria nº 888 (Bezerra et al., 2017; Silva et al., 2020; Lima et al., 2020; Silva et al., 2021). Salienta-se que a União Europeia tem enfatizado em dois marcadores para potabilidade microbiológica: Enterococci sp. e E. coli. Em virtude disso, os motivos que levaram a substituições dos coliformes fecais por Enterococci são a presença de inúmeras espécies integrando a flora intestinal, resistência ao cloro e indicativo da presença concomitante de vírus (Soares; Ferreira, 2017). Para tanto a detecção de vírus e fungos na água até o momento não é uma realidade, por conta da dificuldade de se encontrar marcadores para esses organismos e métodos eficazes e viáveis que possibilitem ser colocados na identificação (Soares; Ferreira, 2017).

\section{Considerações Finais}

A água desempenha um papel extremamente importante e indispensável à todas as formas de vida, no entanto, nem sempre está em condições adequadas para o consumo humano. Para que a população humana possa consumir água livre de contaminação, parâmetros de potabilidade fornecidos por órgãos e legislações ambientais devem ser considerados. Dentro desse contexto, o presente estudo consistiu em uma revisão integrativa acerca dos parâmetros de potabilidade da água para o consumo humano. Dessa maneira, corrobora-se a utilização de análises físico-químicas (cor, turbidez, temperatura, oxigênio dissolvido, cloro livre, pH, etc.) e microbiológicas (contagem de bactérias heterotróficas, Coliformes Totais, Termotolerantes e 
E. coli) como critérios de avaliação da potabilidade da água. A partir desses principais indicadores, busca-se realizar avaliações a fim de atender aos padrões de qualidade da água estabelecidos no Brasil regulamentados pela Portaria GM/MS nº 888, de 4 de maio de 2021, a qual substitui o Anexo XX da Portaria de Consolidação n ${ }^{\circ}$ 5. Os parâmetros e indicadores da qualidade da água eventualmente podem indicar a existência de poluentes e impurezas quando atingem valores superiores aos estabelecidos para determinada utilização. Dessa forma, o Ministério da Saúde e outros órgãos regulamentadores definem os critérios de qualidade e potabilidade da água para consumo humano. Ressalta-se que, desde a primeira portaria BSB $\mathrm{n}^{\circ} 56$, de 14 de março de 1977 até a atual portaria GM/MS nº 888, de 4 de maio de 2021, novas definições foram acrescentadas e outras ajustadas, e o número de parâmetros monitorados aumentou significativamente decorrente do suporte tecnológico. Analisando a nova portaria e os limites permissíveis, observou-se uma alteração e adequação nos valores de algumas variáveis, como por exemplo, pH e turbidez. Desse modo, a portaria mais recente fortalece a noção de padrão de potabilidade e da qualidade da água. Além disso, indicadores de microrganismos foram ajustados e, feito isto, estabeleceu-se os tempos de contato e concentração dos microrganismos através de análises de temperatura e pH específicos, além da turbidez. Essas mudanças e alterações introduzidas pela nova portaria são de extrema relevância para aplicação correta e eficaz dos produtos de desinfecção. No entanto, embora a atualização dos indicadores tenha proporcionado um aprimoramento do tratamento, futuramente novos parâmetros podem ser necessários para garantir a eficácia da potabilidade da água. Por fim, além do tratamento realizado pelas estações de tratamento de água, o monitoramento para manter o trabalho de potabilidade e, consequentemente, a qualidade da água é extremamente importante para que a população possa consumir água tratada e saudável.

\section{Referências}

Alves, G. S. Avaliação dos parâmetros físico-químicos e microbiológicos de água potável de hospitais das cidades de Crato e Juazeiro do Norte- CE. Relatório de Estágio (Tecnologia em Alimentos) - Instituto Federal de Educação, Ciência e Tecnologia do Sertão Pernambucano, Campus Salgueiro, Salgueiro, PE, 2019 .

Araújo, I. G. de et al. Avaliação físico-química e microbiológica da água consumida no município de Mãe - D’agua- PB. INTESA - Informativo Técnico do Semiárido (PombalPB), v 11, n 1, p 07 - 11, jan - jun, 2017.

Araújo de Sousa, C. R. do N.; Matias, A. O.; Santos Filho, F. C.; Sarmento, R. G.; Gomes, M. F. C.; Costa, M. F. Análise da qualidade da água de três propriedades rurais do município de Floriano- Piauí. Revista Brasileira de Agropecuária Sustentável, [S. 1.], v. 9, n. 2, 2019. DOI: 10.21206/rbas.v9i2.3877. https://periodicos.ufv.br/rbas/article/view/3877.

Araújo, D. L.; Andrade, R. F. Qualidade Físico-Química e Microbiológica da água utilizada em bebedouros de instituições de ensino no Brasil: Revisão Sistemática da Literatura. Braz. J. Hea. Rev., Curitiba - PR, Brasil, v. 3, n. 4, p. 7301-7324. Jul/Ago, 2020.

Baptista Neto, J. A.; Wallner-Kersanach, M.; Patchineelam, S. M. Poluição Marinha. 1.ed. Rio de Janeiro: Interciência, 2008.

Bauchspiess, K. Monitoramento de variáveis ambientais e avaliação do índice de qualidade da água em viveiro de piscicultura. 2020 . Trabalho de Conclusão de Curso (Graduação em Engenharia Ambiental e Sanitária) - Universidade Federal de Santa Maria, Frederico Westphalen, RS, 2020.

Bezerra, A. D. A. et al. Análise situacional da qualidade de água subterrânea oriunda de poços da região metropolitana de Fortaleza, Ceará, Brasil. Acta Biomedica Brasiliensia, v. 9, n. 1, p. 94-104, 2018.

Bezerra, A. D. A. et al. Análise da potabilidade de água de chafarizes de dois bairros do município de Fortaleza, Ceará. Acta Biomedica Brasiliensia, v. 8, p. 24-34, 2017.

Birkheuer, C. de F. et al. Qualidade físico-química e microbiológica da água de consumo humano e animal do Brasil: análise sistemática. Caderno pedagógico, Lajeado, v. 14, n. 1, p. 134-145, 2017.

Brasil. Portaria GM/MS no 888, de 4 de Maio de 2021. Altera o Anexo XX da Portaria de Consolidação GM/MS no 5, de 28 de setembro de 2017, para dispor sobre os procedimentos de controle e de vigilância da qualidade da água para consumo humano e seu padrão de potabilidade. https://bvsms.saude.gov.br/bvs/saudelegis/gm/2021/prt0888_07_05_2021.html.

Brasil. Portaria de Consolidação n. 5, de 28 de setembro de 2017. Capítulo V - Da Vigilância em Saúde. Anexo XX - Controle e vigilância da qualidade da água para consumo humano e seu padrão de potabilidade. Brasília: Ministério da Saúde, 2017. https://portalarquivos2.saude.gov.br/images/pdf/2018/marco/29/PRC-5-Portaria-deConsolida----o-n---5--de-28-de-setembro-de-2017.pdf.

Brasil. Manual de controle da qualidade da água para técnicos que trabalham em ETAS / Ministério da Saúde, Fundação Nacional de Saúde. - Brasília: Funasa, 
<http://www.funasa.gov.br/documents/20182/38937/Manual+de+controle+da+qualidade+da+\%C3\%A1gua+para+t\%C3\%A9cnicos+que+trabalham+em+ET AS+2014.pdf/85bbdcbc-8cd2-4157-940b90b5c5bcfc87>

Brasil. Conselho Nacional do Meio Ambiente (CONAMA). Resolução no 430. Diário Oficial [da] República Federativa do Brasil. Brasília, DF, 16 mai. 2011(a).

BRASIL. Ministério da Saúde (MS). Portaria 2.914. Diário Oficial [da] República Federativa do Brasil. Brasília, DF, 14 dez. 2011(b).

Brasil. Conselho Nacional do Meio Ambiente (CONAMA). Resolução no 396. Diário Oficial [da] República Federativa do Brasil. Brasília, DF, 03 abr. 2008.

Castro R. S., Cruvinel V. R. N. E Oliveira J. L. M. Correlação entre qualidade da água e ocorrência de diarreia e hepatite A no Distrito Federal/Brasil [Artigo] // Scielo - Saúde em Debate. - 13 de janeiro de 2020.

Companhia Ambiental do Estado De São Paulo (CETESB), Qualidade das águas superficiais no estado de São Paulo e relatório de qualidade das águas interiores no estado de São Paulo. Apêndices A-Q + anexo A. São Paulo: CETESB, 2020. <https://cetesb.sp.gov.br/aguas-interiores/publicacoes-erelatorios/>

Companhia Ambiental Do Estado De São Paulo (CETESB), Qualidade das Águas Interiores no Estado de São Paulo. Apêndice D - Índices de Qualidade das Águas, 2018. <https://cetesb.sp.gov.br/aguas-interiores/wpcontent/uploads/sites/12/2018/06/Ap\%C3\%AAndice-D-\%C3\%8Dndices-de-Qualidade-das$\%$ C3\%81guas.pdf >

Copasa - Companhia de Saneamento de Minas Gerais. Água não tratada é porta aberta para várias doenças. 2020

Correa, G. Análise da qualidade da água de uma nascente localizada no bairro do Registro, Taubaté, SP - Brasil. Revista Biociências - Universidade de Taubaté - v. 26- n.1 - p. 52-69, 2020

Crispim, D. L. et al. Análise físico-química das águas de três poços Amazonas no centro da cidade de Pombal-PB. Geografia Ensino \& Pesquisa, v. 21, n. 2, p. $155-163,2017$.

Cruz, G. J. R. Parâmetros físico-químicos e microbiológicos da água dos bebedouros de escolas públicas estaduais de tempo integral de Teresina- Pi. 2018. Trabalho de Conclusão de Curso (Tecnologia em Alimentos) - Instituto Federal de Educação, Ciência e Tecnologia do Piauí, Teresina, 2018.

Davis M. L. E Masten S. J. Princípios de Engenharia Ambiental [Livro]. -Porto Alegre: AMGH; 3a Edição, 2016.

Assis, Davisson Márcio Silva et al. Avaliação dos Parâmetros Físico Químicos da Água de Abastecimento em Diferentes Bairros do Município de Salvaterra (Arquipélago do Marajó, PA). Revista virtual de Química. 9. n. 5, 2017.

Filho, D. Caracterização da qualidade da água de Pau dos Ferros quanto a parâmetros físico-químicos. Centro Multidisciplinar de Pau dos Ferros. Trabalho de Conclusão de Curso - Universidade Federal Rural do Semi-Árido, 2019. < http://repositorio.ufersa.edu.br/handle/prefix/2256>

Ferreira, L. A.; Pimentel, E. T.; Silva, R. B. P.; Santos, A. A. Avaliação da qualidade de potabilidade da água subterrânea em áreas rurais no município de Humaitá/AM. Revista Ibero Americana de Ciências Ambientais, v.12, n.1, p.721-729, 2021. DOI: http://doi.org/10.6008/CBPC2179-6858.2021.001.0058

Food Safety Brazil, 2018. Coliformes Totais e Coliformes Termotolerantes. <https://foodsafetybrazil.org/coliformes-totais-ecoliformestermotolerantes-vocesabe-diferenca/

Landa, G. G. et al. Avaliação do uso do cercamento como método de preservação de nascentes e da qualidade dos mananciais. Acta Biologica Brasiliensia, v.2, n.1 (2019) ISSN online 2596-0016

Leite, D. Da S. M. et al. Análise físico-química e microbiológica da água de bebedouros do instituto federal do Maranhão - campus Codó. 2018. < doi: https://doi.org/10.31692/2526-7701.iiicointerpdvagro.2018.00021 >

Lima et al. Avaliação de parâmetros de potabilidade da água e de consumo do Instituto Federal Catarinense-Campus Araquari. Instituto Federal Catarinense Campus Araquari, 2019.

Lima, A.R. de, Santos, R. da C. e Silva, G.C. da. 2020. Avaliação da qualidade da água em bebedouros em escolas de Ensino Fundamental I de cidade do Sertão do Pajeú-PE. Revista Brasileira de Educação e Saúde. 10, 2 (abr. 2020), 45-49. DOI:https://doi.org/10.18378/rebes.v10i2.7557.

Lopes, Daniel Victor Silva. Avaliação do impacto ambiental e associação entre a exposição à água contaminada e o risco de desenvolvimento de doenças de veiculação hídrica em uma reserva extrativista / Daniel Victor Silva Lopes. - Maceió, 2020. 108 f. : il. Dissertação (Mestrado em Sociedade, Tecnologias e Políticas Públicas) - Centro Universitário Tiradentes UNIT/AL

Machado et al. A falta de saneamento básico e sua relação com a hepatite A - uma abordagem descritiva sobre a doença. Revista Saúde em Foco - Edição ${ }^{\circ}$ 13- Ano: 2021

Ministério Da Saúde. Portaria de Consolidação n. 5, de 28 de setembro de 2017. Anexo XX - Controle e vigilância da qualidade da água para consumo humano e seu padrão de potabilidade. Brasília, 2017.

Molluce, Donald. Estudo da potabilidade da água e a importância de seu controle de qualidade no fluxo de produção das indústrias farmacêuticas. 2021. 54 páginas. Trabalho de Conclusão de Curso (Graduação em Engenharia Química) - Universidade Federal da Integração Latino-Americana, Foz do Iguaçu, ano.

Monteiro, G. F. Análises físico químicas das águas de poços tipo cacimba na cidade de Areia - PB, 2018. Areia - PB; https://repositorio.ufpb.br/jspui/bitstream/123456789/11100/1/GFM03082018.pdf;

Morais, W. A., et al. Qualidade sanitária da água distribuída para abastecimento público em Rio Verde, Goiás. Brasil, Caderno de Saúde Coletiva, n. 24, v. 3, p. 361-367, 2016. 
Nolasco, G. M.; Gama, E. M.; Reis, B. M.; Reis, A. C. P.; Gomes, F. J. S.; Matos, R. P. Análise da alcalinidade, cloretos, dureza, temperatura e condutividade em amostras de água do município de Almenara/MG. Recital - Revista de Educação, Ciência e Tecnologia de Almenara/MG, [S. 1.], v. 2, n. 2, p. 52-64, 2020. DOI: 10.46636/recital.v2i2.60. <https://recital.almenara.ifnmg.edu.br/index.php/recital/article/view/60>

Oliveira, E. J. C. de. et al. Análise físico-química e microbiológica da água de bebedouros de escolas municipais na cidade de jardim - Ceará. Visão Acadêmica, Curitiba, v.20 n.1, Jan. - Mar./2019.

Oliveira, M. L. V. M. Gestão de águas, territórios e desenvolvimento econômico. ACTA Geográfica, Boa Vista, v.11, n.27, p.42-61, 2017.

Queiroz, Â. M. de., et al. Qualidade da água de bebedouros em escolas públicas de Mossoró. Revista Biociências, Taubaté, v. 23, n. 1, p. 46-52, 2017

Rabelo et al. Análise dos parâmetros físico-químicos e microbiológicos da água do rio Paciência, São Luís, MA. Revista Ceuma Perspectivas, Edição Especial. I Fórum de Meio Ambiente do Estado do Maranhão, Ceuma. Vol. 30, no01, 2018. DOI:10.24863/rccp.v30i1.201>

Ribeiro, N. P. Avaliação da qualidade da água em reservatório influenciada pelas diferentes configurações de saída. Trabalho de Conclusão de Curso Instituto Federal de Educação, Ciência e Tecnologia de Goiás: Campus Aparecida Goiânia, Bacharelado em Engenharia Civil, 2018.

Santos, M. C. et al. Determinação de propriedades físico-químicas de águas do chafariz do município de Cuité-PB. Educação, Ciência e Saúde, v. 6, n. 1, p. $19,2019$.

Silva, D. R. C da. Análise da qualidade físico-química e microbiológica da água de bebedouros distribuídos em três escolas públicas da zona rural do município de Arapiraca - AL. Trabalho de Conclusão de Curso de Ciências Biológicas - Licenciatura, da Universidade Federal de Alagoas - UFAL, Campus de Arapiraca, 2018.

Silva et al. 2017. Parâmetros físico-químicos da água utilizada para consumo nas escolas municipais da zona urbana de Esperança/PB. Revista Brasileira de Gestão Ambiental (Pombal -PB -Brasil), v. 11, n.01, p.36 -41, jan-dez, 2017

Silva et al. Qualidades das águas fornecidas por bebedouros destinados ao consumo humano e sua relação com a saúde. Braz. J. Hea. Rev., Curitiba, v. 3, n. 1, p. 777-784 jan./feb. 2020. < DOI:10.34119/bjhrv3n1-061>

Silva et al. Qualidade da água designada ao abastecimento público de Rio Branco - Acre. DêCiência em Foco. ISSN 2526-5946 2020; 4(1): 140 - 150 v. 4, n. $1(2020)$

Silva, L. B. Avaliação dos parâmetros da qualidade de água produzida na estação de tratamento de água oeste. 2017.53 f. Trabalho de Conclusão de Curso (Graduação em Química Bacharelado) - Universidade Federal do Ceará, Fortaleza, 2018.

Silva, T. L. da, et al. Avaliação de risco relativo de doenças de veiculação hídrica de fontes de abastecimento individual de água subterrânea localizadas no Bairro Guriri, São Mateus - ES. In: Base de conhecimentos gerados na engenharia ambiental e sanitária 3 / Organizador Cleiseano Emanuel da Silva Paniagua. Ponta Grossa - PR: Atena, cap. 17,p. 204-356, 2021. <https://biblioteca.incaper.es.gov.br/digital/bitstream/123456789/4193/1/soares.pdf>

Silva, R. R. et al. Avaliação da qualidade microbiológica e físico-química da água de um trecho do Rio Capibaribe, no município de São Lourenço da Mata, Pernambuco, Brasil. Brazilian Journal of Development, Curitiba, v. 7, n. 6, p. 62847-62866 jun. 2021

Soares, E; Ferreira, R. Avaliação da qualidade da água e a importância do saneamento básico no Brasil. Revista Meio Ambiente e Sustentabilidade. 13.10.22292/mas.v13i6.762. (2017).

Souza, Sousa. Potabilidade da água de cacimbas: estudo de caso em um distrito da cidade de barro, Ceará. Brazilian Journal of Biosystems Engineering v. 14(4) $321-328,2020$

Souza, Juliano Santos de. Universidade Federal do Rio Grande do Sul. Escola de Administração. Curso de Especialização em Gestão em Saúde (UAB). Trabalho de conclusão de especialização, 2019.

Tortora, G.J.; Funke, B.R.; Case, C.L. Microbiologia. 12. ed. Ed. Artmed. 2017.

Tozzo, R. A.; Gonçalves, E. A. Análise Físico química da Água do Riacho Japira, Localizado no Município de Apucarana-PR. Revista Meio Ambiente e Sustentabilidade, v. 6, n. 3, p. 296-307, 2014. 